IZA DP No. 4992

Disease Prevalence, Disease Incidence, and Mortality in the United States and in England

James Banks

Alastair Muriel

James P. Smith

June 2010 


\title{
Disease Prevalence, Disease Incidence, and Mortality in the United States and in England
}

\author{
James Banks \\ University College London \\ and Institute for Fiscal Studies \\ Alastair Muriel \\ Institute for Fiscal Studies \\ James P. Smith \\ RAND and IZA
}

Discussion Paper No. 4992

June 2010

IZA

P.O. Box 7240

53072 Bonn

Germany

Phone: +49-228-3894-0

Fax: +49-228-3894-180

E-mail: iza@iza.org

Any opinions expressed here are those of the author(s) and not those of IZA. Research published in this series may include views on policy, but the institute itself takes no institutional policy positions.

The Institute for the Study of Labor (IZA) in Bonn is a local and virtual international research center and a place of communication between science, politics and business. IZA is an independent nonprofit organization supported by Deutsche Post Foundation. The center is associated with the University of Bonn and offers a stimulating research environment through its international network, workshops and conferences, data service, project support, research visits and doctoral program. IZA engages in (i) original and internationally competitive research in all fields of labor economics, (ii) development of policy concepts, and (iii) dissemination of research results and concepts to the interested public.

IZA Discussion Papers often represent preliminary work and are circulated to encourage discussion. Citation of such a paper should account for its provisional character. A revised version may be available directly from the author. 


\section{ABSTRACT \\ Disease Prevalence, Disease Incidence, and Mortality in the United States and in England ${ }^{*}$}

We find disease incidence and prevalence are both higher among Americans in age groups 55-64 and 70-80 indicating that Americans suffer from higher past cumulative disease risk and experience higher immediate risk of new disease onset compared to the English. In contrast, age specific mortality rates are similar in the two countries with an even higher risk among the English after age 65. Our second aim explains large financial gradients in mortality in the two countries. Among 55-64 year olds, we estimate similar health gradients in income and wealth in both countries, but for 70-80 year old, we find no income gradient in UK. Standard behavioral risk factors (work, marriage, obesity, exercise, and smoking) almost fully explain income gradients among 55-64 years old in both countries and a significant part among Americans 70-80 years old. The most likely explanation of no English income gradient relates to their income benefit system. Below the median, retirement benefits are largely flat and independent of past income and hence past health during the working years. Finally, we report evidence using a long panel of American respondents that their subsequent mortality is not related to large changes in wealth experienced during the prior ten year period.

JEL Classification: $\quad$ I10

Keywords: health

Corresponding author:

James P. Smith

RAND

1776 Main Street

P.O. Box 2138

Santa Monica, CA 90407

USA

E-mail: smith@rand.org

\footnotetext{
* This research was funded by grants from the National Institute of Aging. Additional co-funding from the Economic and Social Research Council through the ESRC Centre for the Microeconomic Analysis of Public Policy at IFS (CPP) is gratefully acknowledged. Excellent programmer assistance was provided by Iva Maclennan and David Rumpel.
} 


\section{Introduction}

International comparisons of health outcomes have risen in importance as a method of gaining insight into social and economic determinants of health status. Partly, this is because some key institutions- such as the way health insurance or income security is provided—vary more systematically and perhaps exogenously across rather than within countries. In a recent widely cited paper, we compared disease prevalence among middle age adults 55-64 years old in England and in the United States (Banks et al. 2006). Based on self-reported prevalence of seven important illnesses (diabetes, heart attack, hypertension, heart disease, cancer, diseases of the lung, and stroke), Americans were much less healthy than their English counterparts, differences that were large along all points of the socioeconomic status distribution.

Moreover, using biological markers of disease, we found similar health disparities between Americans and the English, suggesting that these large health differences are not simply a result of differential reporting of illness in the two countries. They also exist with equal force among both men and women (Banks et al.2009). Since we purposely excluded minorities (African-Americans and Latinos in American and immigrants in England), these differences were not solely due to American health issues in the African-American or Latino populations or the growing immigrant population in England. Finally, these disparities in prevalence of chronic illness were not the consequence of differences between the two countries in conventional risk factors such as smoking, obesity, and drinking. Health disparities were essentially unchanged when we controlled for different levels of these risk factors in America and in England.

There were several limitations of the previous analysis. First, all health outcomes examined were based on disease prevalence limited to a relatively narrow age group-those 
between ages 55-64. Second, even with an expansion into other age groups, comparisons of disease prevalence by themselves do not inform us about differences in the contemporaneous risk of disease or disease incidence in the two countries. Third, we ignored the most widely studied cross-national health marker in demographic and health research—mortality. These limitations are addressed in this paper.

While data on mortality, disease incidence, and disease prevalence in the two countries turn out not to be contradictory, they do raise some fundamental questions about how these distinct health outcomes are inter-related. These issues are addressed in several ways. First, we expand our prevalence portrait to an older age group—-70-80 years old— to evaluate whether the English health advantage in chronic disease persists into older ages. Next, we investigate patterns of disease incidence more directly by documenting disease incidence in America and England for the same age groups.

In spite of higher rates of disease incidence and prevalence in America compared to England, age specific mortality rates are not dissimilar when people are in their sixties and are somewhat higher in England compared to America after age seventy. Higher rates of both disease prevalence and incidence in America are still consistent with similar life expectancies in the two countries if incident mortality upon diagnosis is greater in England than in America.

The second goal of this paper concerns the role of financial resources in affecting mortality differences in England and the United States. The causal role played by individual and financial resources in directly affecting mortality has always been controversial, a debate that has been renewed in recent years as demographers (Rogers et. al 2000), epidemiologists (Adler et al. 2008; Lynch et al.2004), economists (Smith 1999) and sociologists (Mirowsky and Ross 2003) all bring their alternative perspectives to this issue. Using panel data matched to national death 
indexes, we analyze determinants of mortality in both countries with an emphasis on the question of the comparative nature of income and wealth gradients in mortality. Since the seminal demographic work of Kitagawa and Hauser (1973), the relationship between economic status and subsequent mortality has remained very controversial. The addition of excellent micro-data panels such as the HRS and ELSA containing rich income and wealth modules linked to the subsequent death of their respondents is an important advance in quality of data.

This paper is divided into four sections. The first briefly summarizes the data and major variables used in our analysis. Section 2 highlights salient comparative patterns in disease prevalence, incidence, and mortality in England and the United States. The third section contains empirical models that investigate the impact of economic, demographic, behavioral risk variables and health status variables on comparative mortality in the two countries. The final section summarizes our main conclusions.

\section{Data}

In this paper, we examine health differences for middle age and older people in England and America. The English-American comparison is of interest for several reasons. First and foremost, with the advent of HRS and ELSA the quality of micro-data with biomarkers and links to national death indexes is by far the best to simultaneously consider disease prevalence, incidence, and mortality. Moreover, work subsequent to our original paper confirmed that the American health disadvantage in disease applies when America is compared to many Western European countries (Avendano et al. 2009). As we show below, trends in mortality by age between America and England parallel those for many countries in the West.

For the United States, our research is based on the Health and Retirement Survey (HRS), a nationally representative panel survey that currently includes over 20,000 people in the over- 
age 50 populations in the United States (Juster and Suzman 1995). HRS began in 1991 with its original cohort ages 51-61 and new cohorts have been subsequently added to maintain population representation of this age segment. Respondents are re-interviewed biannually.

For England, we use the English Longitudinal Survey of Aging (ELSA) which contains around 12,000 respondents recruited from three separate years of the Health Survey for England (HSE) survey to provide a representative sample of the English population aged 50 and over. ${ }^{1}$ The health data were supplemented by collection of baseline social and economic data in the first wave of ELSA fielded in 2002. Like HRS, follow-ups are conducted every two years and currently the first three waves are in the public domain.

Both HRS and ELSA are known to have high quality measurement of several dimensions of social-economic status_education, income, and wealth. Income is asked separately for both spouses for each of its major sub-components—earnings, pensions, social security or state pensions, and income from capital. A unique aspect of these surveys is that they both contain high-quality wealth modules using a comprehensive and detailed set of questions on the important components of wealth (Juster and Smith 1997).

\section{Measurement of Disease Prevalence, Incidence, and Mortality}

The health outcomes measured in this research are disease prevalence, disease incidence and mortality. For the first two, we restrict ourselves to diseases that can be comparably measured in the two countries. For prior lifetime prevalence, both surveys basically collect data on individual self-reports of specific diseases of the general form 'Did a doctor ever tell you that you had ...' The specific diseases included are diabetes, hypertension, heart disease, heart attack, stroke, chronic lung diseases, and cancer. Since these questions are asked in each wave,

\footnotetext{
${ }^{1}$ HSE is a series of annual health surveys beginning in 1991 covering the adult population aged 16 and over living in private households in England. The contents of the core model vary by year. It has no panel component.
} 
prevalence as well as incidence ${ }^{2}$ of disease can be calculated among panel participants as new onsets of disease are diagnosed as waves of the panel unfold. Whilst we cannot now look at biomarker based measures of disease in the complete data used here, we know from our earlier study that biomarkers give us the same ranking of disease prevalence in the two countries.

While questions on disease prevalence are quite similar in ELSA and HRS, there are some differences in implementation to keep in mind. In 2002, when the ELSA baseline information was collected, many HRS respondents had been panel members for up to ten years. Questions about disease prevalence had been asked of these respondents up to five times and in each new wave the respondent was asked to verify his/her previous diagnosis if positive. The other major difference is that while HRS probes disease prevalence asking about each disease separately, ELSA shows its respondents a list of diseases on a 'show card'. It then asks respondents to name chronic diseases they have. Especially for less serious chronic conditions, there is a legitimate question whether 'show card' lists understate disease prevalence. We present some evidence on this issue below.

There are essentially two ways by which mortality status of ELSA and HRS survey participants can be identified. The first is when, as a consequence of attempts to interview respondents for the next survey wave, the survey organization finds that the respondent is deceased. In addition, both ELSA and HRS are matched to each country's National Death Index, which includes information about date and cause of death of all respondents regardless of their participation in subsequent waves of the survey. ${ }^{3}$ These matches with the national death indexes are highly successful- over 95\% of individuals give permission for their records to be linked and are successfully matched. In this paper, we concentrate on the mortality outcomes in two age

\footnotetext{
${ }^{2}$ While we use the term incidence throughout this paper, a more accurate term is new detection.

${ }^{3}$ In each country, the linked data (the National Death Index in the US and the National Health Service Central Register Database in England) is the data which, at the population level, is used to compute official life tables.
} 
groups - those 55-64 and those 70-80 years old in 2002 —and limit our analysis to non-Hispanic whites in both countries so that the health disparities documented are not simply due to the health problems of minority groups in each country.

\subsection{Comparisons of Disease Prevalence and Incidence in the United States and in England}

Table 1 presents our basic data on disease prevalence for those 55-64 years old and those ages 70-80 in England and the United States. To provide a common time frame, prevalence is listed for calendar year 2002, the ELSA baseline year. For each disease, in the 55-64 year old age range Americans are considerably sicker than the English and for many diseases differences are quite large, replicating the basic finding in Banks et al. (2006). To illustrate, diabetes prevalence is twice as high in the United States as in England (12.1\% compared to 5.9\%) and cancer prevalence is $74 \%$ higher in the America compared to England (9.6\% compared to 5.5\%).

Table 1 also contains estimates of disease prevalence among those 70-80 years old. Given the sharp age gradient in disease, prevalences are not surprisingly much higher among those in their seventies as aging takes its inevitable toll. More importantly, we find the same country ranking for those in their seventies as disease prevalence remains higher among Americans than the English. For cancer, diabetes, and heart problems, American excess disease is equally large in absolute value among those in their seventies.

Since they are computed from panel studies, disease prevalences in Table 1 based on ELSA and HRS contain potential sources of bias. As mentioned above, ELSA obtained data using 'show card' lists and HRS was updating information obtained in previous waves. To check on the possibility that these potential biases could affect inter-country comparisons, Table 1 also lists estimates of disease prevalence obtained from the best cross-sectional health surveys in each country - the Health Survey for England (HSE) and the National Health Interview Survey 
(NHIS) in the United States. While there are some differences between estimates obtained from ELSA and HRS and the cross-sectional 'gold standards', ranking of the countries remains intact-Americans are sicker than the English. The one large difference that emerges is hypertension prevalence in England which is four or five percentage points higher in the HSE. We believe that this may reflect an understatement in ELSA due to the use of 'show cards' to measure prevalence, as discussed above.

The fifth and sixth rows in each age panel in Table 1 list 2002 disease prevalence in these age cohorts for those who remained in the survey in the two subsequent waves until to 2006. Prevalence among respondents who neither died nor left the study are lower than prevalences in the first row largely due to the higher levels of disease among those who died by 2006. However, this panel sample based estimate of disease prevalence also preserves the ranking of the two countries with Americans still seen as much sicker than the English. .

Table 2 reports our measures of disease incidence. The first measure involves computing disease incidence among those in HRS and ELSA who were interviewed in both in 2002 and $2006^{4}$. The second is based on differences in prevalence between cross-sectional estimates of prevalence where the synthetic cohort sample is allowed to age by four years (using NHIS in the United States and HSE for England).

Each alternative method has advantages and disadvantages. Within-panel estimates of incidence are for survivors only where surviving means that respondents neither died nor left the study between 2002 and 2006. Attrition from the study does not affect ranking of estimates based on changes in cross-section data. If these were closed cohorts, on average differences in crosssectional prevalence allowing a cohort to age would not be biased estimates of incidence on

\footnotetext{
${ }^{4}$ There is no requirement that they also participated in the 2004 wave.
} 
average. But these are not closed cohorts mostly to do with mortality. ${ }^{5}$ Since those who subsequently died had higher baseline prevalence, synthetic cohorts created from cross-sections will understate new incidence among survivors since baseline prevalence of survivors only would be smaller. Mortality is relatively low in the 55-64 year old age group so this age group will not be affected much by this bias, but that may not be true among those 70-80 years old.

Using either method however, Table 2 shows that incidence of disease is generally higher in America than in England amongst those in the 55-64 year old age group. ${ }^{6}$ Americans in this age group not only suffer from higher past cumulative disease risk as indicated by their higher disease prevalence; they also experience higher immediate risk of new disease onset or incidence compared to the English. Estimates of incidence are much closer in the 70-80 year age group with a slight edge toward higher incidence among Americans.

\subsection{Comparisons of Mortality in the United States and in England}

Micro-data from HRS and ELSA allow us to compare determinants of mortality at older ages in the two countries. A natural starting question is the degree to which mortality as revealed by these micro surveys matches mortality from the national death index in both countries.

Figure 1 presents the relevant comparison for the United States while Figure 2 displays a parallel comparison for England for all ages 50 and over. For both the national death index and the micro

\footnotetext{
${ }^{5}$ Another reason would be new immigration or emigration but this is likely to be small in these age groups.

${ }^{6}$ The primary exception to the rule relates to onset of hypertension within the panel. We speculate that this results from an understatement of hypertension prevalence in baseline ELSA due to the use of show cards with multiple disease categories. Respondents are asked to list all conditions but may well prioritize their major conditions at baseline. When they are asked in subsequent waves about conditions not mentioned in previous waves, these preexisting minor conditions, such as hypertension, will be reported. As a result initial prevalence would be lower and subsequent incidence higher, until the panel reaches maturity. Note that when we use the synthetic cohort estimation (show cards are not used in HSE, which instead follows the HRS and NHANES methodology), hypertension onset is higher in the US compared to England.
} 
survey data in each country, these figures represent the probability of surviving over the same time interval- from the end of year 2002 to the end of year in $2006{ }^{7}$

HRS data on respondent mortality are remarkably close to those obtained from the American life table (Arias 2004). ${ }^{8}$ At all ages 50 and above, the two mortality curves closely overlap with the only difference being the larger random component in the survey data especially at older ages when numbers of living respondents in the HRS sample become relatively thin (see Figure 1). Over this age range, there does not appear to be any systematic difference between the national death registry and HRS based estimates of the four year probability of survival by age.

As demonstrated in Figure 2, this close correspondence is not the case in England. After age 65, mortality among ELSA respondents is somewhat lower than mortality in the English national death index (GAD). The most likely explanation for this discrepancy is that compared to HRS, ELSA is an immature survey in the sense that it has not yet reached population representative steady state. ELSA's baseline sample in 2002 was drawn from the noninstitutionalized population thereby leaving out those residing in nursing homes whose mortality prospects especially at older ages are higher than average. A similar bias existed in the original HRS sample of older respondents (AHEAD sample of those ages 70-80 fielded in 1993). Since respondents are subsequently followed into nursing homes in both the HRS and ELSA samples this bias no longer exists in the older HRS sample but is still present in ELSA.

Our aim is to contrast the pattern of older age mortality in the two countries. Figure 3.A compares post age 50 year survival probabilities in England and the United States using country

\footnotetext{
${ }^{7}$ The American national data on the age specific probability of survival comes from the CDC Arias (2004) and the English data comes from UK Government Actuary Department (GAD). All data represent the probability of surviving from 2002 to 2006

${ }^{8}$ The CDC life tables are for Whites while HRS is for Non-Hispanic Whites. Doing HRS for all Whites yields similar results.
} 
specific national death indexes as the yardstick, while Figure 3.B switches the metric to the two national household surveys_ELSA and HRS. Using national death indexes, the probability of dying is only slightly higher in the United States compared to England before age 65. After age 70, however, mortality probabilities are higher in England than in America and hence remaining life expectancy is lower. As indicated by the graphs in Figure 3.B, the patterns of roughly equal mortality between the two countries before age 65 is confirmed by survey data. After age 65 , the probability of death appears to be higher in HRS than among ELSA respondents even though we know from the national death indexes that the opposite is the case.

At these ages, controlling for age, disease prevalence is higher in America than in UK as is new disease incidence-but the English have higher age specific all cause mortality. Is it possible to reconcile higher rates of disease prevalence and disease incidence in the United States compared to England alongside higher post-age 65 age specific mortality in England? There are two possible explanations. The first is that true incident mortality from disease is shorter in England than in America. The second is that true incident mortality is the same in both countries, but that the English are diagnosed at a later stage in the disease process than Americans are. ${ }^{9}$

With the available data, we cannot separate the relative role played by these two factors and it is most likely a combination of the two. Whatever the weights assigned to these explanations, both imply higher quality medical treatment broadly defined in the United States compared to England at least in the sense that mortality implications of disease are less severe in America. A broad definition of quality treatment includes accurate and timely diagnosis,

\footnotetext{
${ }^{9}$ The delayed diagnosis of disease cannot be so severe that it is camouflaging the data on disease prevalence since when we have biomarker data the self-reported and biomarker determined prevalences are similar—at least up to the age of 70 (see Banks et al. 2009).
} 
effective treatment of the disease, and good patient compliance with medication, personal behaviors, and follow-up visits and/or treatment.

Cancer is a good illustrative example. The United States is believed to screen and capture earlier in the progression of disease, particularly for prostate and breast cancer (Melia et al. 2004; Preston and Ho 2009a; Sirovich et al. 2003). Partly due to more aggressive screening, Preston and Ho (2009a) report higher five year cancer survival rates in America compared to Europe. Our findings are consistent with this evidence on cancer but extended on average to all cause mortality. To the extent that increased screening intensity leads to discovery of milder and potentially less fatal occurrences of disease, some part of this empirical relationship may not reflect the direct consequences of health care interventions subsequent to diagnosis. But earlier detection could also be seen in this case as a good attribute of the medical system.

There is a growing body of evidence that the American disadvantage is mortality declines pretty sharply with age. For example, Manton and Vaupel (1995) found that America had quite favorable over age 80 survival compared to other industrialized countries including Japan. While spending for medical treatment has increased over time in America, these increases have been much larger ( $8 \%$ compared to $4.7 \%$ per year) among those post age 65 than among those ages 1-64 (Cutler and Meara 1998). Moreover, these cost increases were concentrated among high cost users —-those with cardiovascular disease — which is consistent with a translation into mortality declines over time for those with cardiovascular disease in America.

Ho and Preston (2009b) report that among 18 OECD countries in 2005 the United States ranked last or next to last in life expectancy until after ages in the mid sixties after which they moved rapidly up the rankings into the top five in survivor probabilities by the mid eighties in age. Ho and Preston conclude that the principal reason is that the American health care system 
performs well for older patients compared to other countries. Fonseca et al. (2009) estimate that technological change explains about $60 \%$ of the rise in life expectancy at age 50 over this period while insurance access and income explained less than $10 \%$.

Disease prevalence, disease incidence, and mortality are three inter-related but distinct measures of population health. The health problem in America compared to England is that Americans in adulthood become much sicker at much earlier ages than the English do and than many other Western Europeans do. Americans spend much more money dealing with this excess illness, money that on average and increasingly has payoffs in reduced mortality consequences of excess disease. While important as well, America's health problem is not fundamentally a health care quality or health insurance problem. It is an excess illness problem, the solution to which may lie primarily outside the health system.

\subsection{Mortality Models}

In this section, we present empirical models that investigate determinants of mortality at older ages. Our emphasis is on evaluating the nature of the mortality gradient with two key financial measures—income and wealth—in England and the United States. We will evaluate how sensitive these financial gradients are to the inclusion of sets of variables that may influence mortality and also be correlated with the financial situation of the household.

There are four models in Table 3 that are placed into four conceptually distinct blocks:

(1) unadjusted or raw differences in mortality by financial quintiles; (2) demographic models that add a full set of age and gender controls; (3) 'behavior’ models that add controls for other nonhealth behaviors widely accepted as related to mortality and to financial gradients, (4) models that control for baseline health status. All models include a set of dummy variables for either income quintiles or wealth quintiles.. 
To first establish unadjusted differences in mortality, model (1) only contains the financial quintiles measures, with quintile 1 representing the poorest $20 \%$ of the population, ranked by income or wealth respectively, and quintile 5 - the richest $20 \%$ of the populationbeing the omitted reference group. To assess the role of gender and age demographic differences, model (2) adjusts for age by including single year age dummies that are allowed to differ by gender. Models in the third column add a standard set of behavioral covariates known to be related to SES and to mortality. Some of these behavioral factors represent social relationsmarital status (Jin and Christakis 2009; Waite and Gallagher 2000); some are alternative measures of SES such as education; ${ }^{10}$ some capture aspects of work such as the two labor market status variables (whether the respondent is working and the number of weeks worked); and some represent a standard set of health behaviors measured in the two surveys (current smoking and ex-smoking status, three categories of obesity ( $30 \leq \mathrm{BMI}<35$; $35 \leq \mathrm{BMI}<40$, and $\mathrm{BMI} \geq 40$ ), overweight $(25 \leq \mathrm{BMI}<30)$, drinking ${ }^{11}$, and vigorous exercise $\left.{ }^{12}\right)$. These variables we label 'behavior' variables. While important in their own right, our interest here does not rest so much in differences amongst these alternative sub-types of behavioral variables, but rather in their collective contribution to accounting for financial gradients in health.

\footnotetext{
${ }^{10}$ In the United States, the three education groups are less than high school, high school graduate but not a college graduate, and college graduate or more. In England, the three education groups are We divide ELSA respondents into three education categories: those with a degree, or higher education below a degree, who are classed as 'high;' those with A-levels, O-levels or equivalent qualifications, who are classed as 'moderate;' those with qualifications below O-level, or no qualifications, who are classed as 'low.'

${ }^{11}$ Heavy drinking in the US is defined as drinking six or seven days a week and in ELSA as at least daily. Moderate drinking is defined in the as one to five days per week .

12 The question on vigorous exercise in the US is "On average over the last 12 months have you participated in vigorous physical activity or exercise three times a week or more? By vigorous physical activity, we mean things like sports, heavy housework, or a job that involves physical labor. In England, ELSA respondents are asked how often they engage in sports or activities that are vigorous in nature, "such as running or jogging, swimming, cycling, aerobics or gym workout, tennis, or digging with a spade or shovel." Those who reply that they do so once a week or more are given a value of 1 ; everyone else is given a zero.
} 
The final model adds a set of baseline health status measures including three categorical variables for self-reported health status (whether respondent is in excellent or very good health, good health, fair health with the omitted group in poor health) and the following list of chronic health conditions (hypertension, diabetes, cancer, lung, heart disease, stroke, and arthritis). These variables we label the 'health status' variables. These variables are conceptually distinct from behavioral variables since they directly relate to the future health outcome being modeled. It is argued that controlling for baseline health status is necessary in order to estimate a causal effect of financial resources on subsequent mortality since past health problems will directly affect the amount of financial resources available to the household (Smith 1999; Smith 2004). We return to this issue in section 3.3 below. These models are estimated separately for each country for two age groups-ages 55-64 and 70-80. All models are estimated using ordinary least squares and coefficients represent the estimated probability of dying over the four year period.

The unadjusted income and wealth gradients for those 55-64 years old contained in column (1) show that, in each country, the probability of death is four to five percentage points higher in the poorest income or wealth quintile compared to the richest one. Even in these unadjusted variants, however, estimated gradients are highly non-linear-much steeper below the median than above it. For example, mortality in the third and forth income quintile in either country tends not to be statistically different than the top income quintile. Among those between ages 55 and 64, both income and wealth gradients are remarkably similar in the two countries with perhaps a slightly higher excess mortality within the lowest income quintile in America.

This similarity in financial gradients across countries is decidedly not the case for those between ages 70 and 80 . In the United States, income and wealth gradients are much steeper than in the pre-retirement years and, while they remain highly non-linear, the gradients do not 
disappear in quintiles above the median. In contrast, there is no income gradient at all in England in this age group while a wealth gradient remains at least below median wealth. We return below to explanations for the absence of income gradients in the older group in England.

Table 3 demonstrates that within these narrow age groups including age and gender controls does not alter the nature of these estimated financial SES gradients in either country. ${ }^{13}$ In contrast, the addition of controls for work, marital status, and health behaviors significantly reduces wealth and especially income mortality gradients. Among those 55-64 years old, there essentially remains a very weak income or wealth gradient, implying that this set of additional covariates placed under the 'behaviors' label is sufficient to account for most of the relationship of income or wealth to mortality. In contrast, the sharp between country differences among those 70-80 years old remains—a reduction but not an elimination of both types of financial gradients in America and a significant reduction of the wealth gradient in England. The nonexistent income gradient in England remains non-existent.

The final column in Table 3 illustrates impacts on financial gradients of adding health status controls. Once again, financial gradients (both income and wealth) are either completely eliminated or with the sole exception of wealth for Americans 70-80 years old substantially reduced when baseline health status controls are added to the model.

Table 4 (for ages 55-64) and Table 5 (for ages 70-80) contain distributions of selected attributes used as predictors in models in Table 3. The first and forth columns are means of attributes in the lowest financial quintile for the United States and England respectively. The second and fifth columns list differences between the third quintile and the first while the third

\footnotetext{
${ }^{13}$ If these models were estimated over the full age range from 50-80 due to the strong negative correlation between age and income. In that age sample, the income gradient is significantly smaller when age controls are added.
} 
and sixth columns contain differences between the highest and lowest quintile. We provide statistical tests of differences in attributes between these quintiles using * for the five percent level and ** for the one percent level. The upper panels in these tables are arrayed by income quintiles and the bottom panel by wealth quintiles.

First consider patterns observed amongst those 55-64 years old for 'behavior' related variables. Table 3 demonstrated that the 'behavior' sub-set of variables were able to account for virtually all financial gradients in mortality in both countries. This is not surprising as Table 4 shows that these 'behavior' variables are all strongly socially graded in both countries.

While obesity declines with financial quintiles, obesity alone contributes little to the observed financial gradients in mortality especially compared to smoking. Current smoking declines rapidly across either income or wealth quintiles. In these birth cohorts in both countries and at all income and wealth levels, a large fraction of individuals who smoked in the past were able to stop. But the fact that current smoking declines more sharply across financial gradients than does ever smoking implies that low income and low wealth individuals find it much more difficult than higher income or wealth individuals to stop smoking once they have started. This pattern is especially true in England.

Exercise, work effort, and marriage are all graded and account for most of the attenuation of the financial gradients when 'behavioral' variables are added to the model. The extent of vigorous exercise increases rapidly with income and wealth, no doubt in part reflecting differences across quintiles in health status of respondents. ${ }^{14}$ Differences in the amount of work across these income quintiles are impressive. Low levels of work are partly the consequence of

\footnotetext{
${ }^{14}$ The levels of vigorous exercise in the US and England cannot be compared due to the differences in question wording in the two surveys.
} 
poor health and therefore primarily indicate causality from health to financial resources (Smith, 2004). Those in the top quintile in America work 22 weeks more a year than those in the bottom income quintile- the comparable number in England is 25 weeks. A large part of that difference in work effort takes place at the bottom quintiles. The fraction of individuals who are married increases rapidly across these income and wealth quintiles

Table 5 contains a similarly structured distribution of attributes for ages 70-80. In these birth cohorts unlike those born fifteen years earlier, the probability of ever smoking does not vary with income. The probability of current smoking does decline with income and is primarily associated with the ability to stop smoking once started. Current smoking is much lower among these older respondents in both countries as $75 \%$ or more have ceased smoking. Not surprisingly given that these are post-retirement years, the strong association of work with income quintile is much more muted in this age group. This is the primary reason for a smaller impact of these behavior variables on the size of financial gradients in this age span.

Given the absence of an income gradient on mortality in England among those 70-80 in Table 3, it is not surprising that health status outcomes in England are much less sharply graded than in America especially along the income metric. In England, it is as likely for the chronic diseases to rise with income quintile as to fall. In England, general health status is only nine percentage points higher in the top income quintile compared to the bottom-the comparable differential in America is 25 percentage points.

\subsection{Why is there no Income Gradient in Mortality in England among the Retired?}

The most dramatic country level difference in financial gradients in mortality is the absence of any income gradient in England among those 70-80 years old. We believe this anomaly reflects institutional differences between the two countries in the provision of income 
security during retirement. Specifically, compared to England, the state provided pension in the United States (Social Security) is both a lower fraction of total retirement income and is much more closely related to past labor market earnings and work (and thus past health status).

To understand how Britain’s state benefit system can ‘decouple’ individuals’ current income from their past income, in a way which the U.S. system does not, it is necessary to know a little about the benefits to which elderly people in England are entitled. The most important of these is the Basic State Pension (BSP), which makes up nearly a third of total government benefit spending in Britain. The BSP is paid to individuals over the state pension age-currently 60 for women and 65 for men, and was worth $£ 76$ (\$122) per week for a single pensioner and $£ 121$ (\$194) weekly for a couple in 2002/03.

While not everyone qualifies for the full rate of BSP (an individual must have made contributions to the National Insurance system for $90 \%$ of their working lifetime ${ }^{15}$ ), coverage among pensioners - especially male pensioners - is very high. This makes the state pension a significant source of income among 70 to 80 year olds - and particularly so for those with below-average income. Figure 4 displays primary sources of income amongst the English in their seventies. Among individuals with income in the bottom six deciles, more than half their income comes from the state pension alone Adding other state benefits accounts for more than three quarters of their total income, on average, even around the median. ${ }^{16}$

\footnotetext{
${ }^{15}$ Defined as the period between age 16 and the state pension age. While $90 \%$ of working life may seem a high bar to qualify for the benefit, individuals are credited with National Insurance Contributions for periods out of the labor market due to illness, disability or unemployment.

${ }^{16}$ Authors' calculations using Family Resources Survey. In addition to state pension system, there are several benefits targeted at elderly people on low incomes. The most important is the Pension Credit Guarantee Element, which tops up incomes of individuals aged 60 and over, to a specified minimum level. Besides having incomes topped up, recipients of guarantee credit are automatically entitled to maximum amounts of several other benefits(housing benefit, council tax benefit and health benefits such as free prescriptions, dental treatment and sight tests).
} 
The fact that the Basic State Pension is an important component of older individuals' incomes, and that it is a broadly flat rate benefit, offers the most plausible explanation for the absence of any income gradient for mortality among 70 to 80 year olds in England. The comparatively generous benefits in England especially at the bottom act to reduce the link between income in retirement and poor health in earlier life. By eliminating the link between past health and income during retirement one loosens the link between post-retirement income and subsequent mortality.

Several alternative explanations for the absence of a mortality gradient in income rely on types of selection effects correlated with income. One form of selection might be that 'healthy survivor effects' are stronger in England. Poorer people in England who survive to the age of 70 or older may be healthier in unobservable ways than their higher income counterparts. Were this case, we would also expect to see no mortality gradient in other measures of socioeconomic status, such as wealth. As demonstrated in Table 3, we see a robust wealth gradient in England in this age group, which argues against ‘healthy survivor’ being a complete explanation.

Another form of selection may be survey induced. As mentioned above, ELSA samples community residents at baseline excluding those in nursing homes who are presumably less healthy. Why this would only flatten the income gradient and not the wealth gradient remains a weakness of this selectivity explanation. The identical sampling bias is also present in the original AHEAD survey when it was fielded (those 70 and over in 1993) since it also was based on community residents. The income gradient in mortality in the AHEAD sample is quite strong.

A parallel question to why the income gradients in mortality are so low in England during these post-retirement years is why they are so high among Americans in this age group, even after we control for our sub-set of "behavior' variables. Our estimated American gradients in 
Table 3 for those between ages 70 and 80 show that income gradients remain high until we control for baseline health status indicators.

A full accounting is beyond the scope of this paper, Table 6 repeats the income gradients present in Table 3. Alongside them, we list in parenthesis estimated income gradients when we exclude income from capital from family income. This source of income matters, especially for the lowest income quintile where the size of the excess mortality for the lowest income quintile is cut by forty percent. Income from capital is largely income earned from assets and the amount of assets held is quite sensitive to past health occurrences (Smith 1999). Poor health during one's life inhibits the ability to accumulate assets and thereby lowers the amount of asset income one has at any time. This empirically strong correlation between income and health most likely reflects a pathway from health to income rather than the other way around.

\subsection{Does Wealth Affect Mortality?}

The final models in Table 3 control for baseline measures of health status and financial resources (income or wealth) and health status variables dominate financial resources which fail to predict subsequent mortality. Using the model in Table 3, however, it is impossible to disentangle the complex pathways and interactions from the past that lead to the co-existence of poor health outcomes and low levels of income or wealth. To estimate the 'effect' of either on the other requires exogenous variation in health (or SES) that is not induced by SES (health). ${ }^{17}$

In this section, we take a step in that direction by estimating pathways from financial SES measures and more particularly household wealth to subsequent mortality. To do so, it is necessary

\footnotetext{
${ }^{17}$ Smith 1999 proposed one research strategy for isolating new health events-the onset of new chronic conditions. While to some extent people may anticipate onset, much of the actual realization and especially its timing may be unanticipated. While new onsets may provide the best chance of isolating health shocks, not all new onset is a surprise. A set of behavioral risk factors and prior health or economic conditions may make some people more susceptible than others to this risk. Thus, predictors of new onsets should be included in models to increase one's confidence that the remaining statistical variation in new onsets is 'news.'
} 
to isolate innovations in household wealth that were not caused by health. One difficulty is testing whether changes in wealth affect subsequent health is that the panel has to be sufficiently long to capture wealth changes that are large enough to significantly alter a household's resources and then allows time to observe any subsequent change in mortality. The best existing data panel to perform such a test is the original HRS cohort (those 51-61 years old in 1992). Those respondents have been interviewed for eight rounds over a fourteen year time period during a time span when large wealth changes occurred, mostly induced by asset price changes in housing and stock markets.

To conduct this analysis, we selected a sample of original HRS respondents who survived until 2002 — the period from 1992-2002 over which we will measure wealth change. Our outcome variable is whether they survived until the end of 2006. Besides placing individuals into wealth quintiles, we placed them into five quintiles based on their observed wealth changes between 1992 and 2002. All other variables in the models are the same as in the wealth analysis presented in Table 3 except that they are measured using the 1992 baseline values. ${ }^{18}$ Quintiles of wealth (again defined at the initial 1992 baseline) are also included in all models. ${ }^{19}$

Our estimated effects for wealth change variables are presented in Table 7 which simply reports coefficients on the ‘change in wealth’ quintiles. Once again the top quintile, in this case those with the greatest accumulation of wealth between 1992 and 2002, is the omitted reference group. The format is similar to Table 3 as parameter estimates are listed first with controls for age, gender and the initial level of wealth only, then adding behavior variables, and finally adding the 1992 health status variables. The final column in Table 7 lists median wealth changes

\footnotetext{
18 The same drinking variables as used in Table 3 are not available in 1992 so drinking behavior is not included.

${ }^{19}$ Due to the short panel in ELSA, we cannot estimate this model for the English sample. Our preliminary investigations, using a 2002 baseline, wealth changes defined between 2002 and 2004, and mortality defined between 2004 and 2006, yield results that are suggestive of the same empirical relationship as found in the US .The short panel means that there is a relatively low level of statistical power in such a model.
} 
within each wealth change quintiles to measure differences between groups. Changes in wealth are quite large even when medians are used- the difference between the bottom and top quintiles is over one-half million dollars and changes in wealth expand as we move up the quintiles.

With the exception of the bottom quintile, estimated effects on mortality of the change in wealth are essentially zero in all specifications in spite of the $\$ 455,000$ wealth change difference across $80 \%$ of the sample. There is no evidence that across most of the sample that increases in wealth- even when large—are protective of subsequent mortality.

Those in the bottom wealth quintile have higher mortality compared to any other wealth change quintiles. But note that their wealth actually fell over this period. A more likely explanation for this result is that these individuals were hit by health shocks which lead them to deplete their assets and wealth in order to finance their consumption, pay their medical bills and perhaps to avoid asset tests in social programs.

At the very least, this analysis suggests a great deal of caution is interpreting coefficients on wealth on health as an indication of a 'causal' effect. More nuanced but complicated scenarios are still possible. Wealth effects may be very asymmetric where losses have effects on health while gains do not. Similarly, wealth effects associated with a lost of a home may be quite different that simply loss of value in a home where one still lives.

\section{Conclusions}

In this paper, we compare rates of disease prevalence, incidence, and mortality in England and the United States. We find that disease incidence and prevalence are both higher among Americans in age groups 55-64 and 70-80 indicating that Americans suffer not only from higher past cumulative disease risk as indicated by their higher disease prevalence; they also 
experience higher immediate risk of new disease onset or incidence compared to the English. In contrast, age specific mortality rates are quite similar in the two countries with an even higher risk among the English after age 65.

We also estimate financial gradients in subsequent mortality in both countries and assess the sensitivity of these financial gradients to the inclusion of 'behavior' variables and baseline health status variables. Among, those 55-64 years old, we estimate similar gradients in both income and wealth in both countries. In contrast, among those 70-80 years old, we estimate a significant financial gradient in both income and wealth in America but no income gradient in UK. Standard behavioral risk factors (work, marriage, drinking, obesity, exercise, and smoking) almost fully explain income gradients among those 55-64 years old in both countries and a significant part of it among Americans 70-80 years old. If we also control for baseline health status, there are no remaining financial gradients in either country in either age group.

The most like explanation of the absence of any income gradient among the English in their post retirement years relates to the nature of their income benefit system during retirement. Especially below the median where the financial mortality gradient tends to be steeper, these benefits are largely flat and thus independent of past income during the working years and therefore largely independent of past health. Without that link to past health, there appears to be no effect of income with mortality in this age group in England.

Finally, we report evidence using a long panel of respondents in the United States that their subsequent mortality is not related to changes in wealth that they experienced during the prior ten year period. This supports the view that the primarily pathway between health and wealth is that poor health leads to a depletion of household wealth. 


\section{References}

Adler, N.E. and D.H. Rehkopf. 2008. “U.S. Disparities in Health: Descriptions, Causes, and Mechanisms.” Annual Review of Public Health 29:235-52.

Arias, E. 2004. “United States Life Tables, 2002.” National Vital Statistics Reports 53(6).

Avendano, M., M. Glymour, J. Banks, and J.Mackenbach.2009. "Health Disadvantage in US Adults Aged 50-74: Are Poor Europeans Healthier than Americans?” American Journal of Public Health 99:540-48,

Banks J., M. Marmot, Z. Oldfield, and J.P. Smith. 2006. “Disease and Disadvantage in the United States and in England.” JAMA 295(17):2037-45.

Banks, J., M. Marmot, Z. Oldfield, and J.P. Smith. 2009. “SES and Health on Both Sides of the Atlantic.” Pp. 359-406 in Developments in the Economics of Aging, edited by D. Wise. Chicago, IL: University of Chicago Press.

Cutler, D. and E. Meara.1998. “The Medical Costs of the Young and the Old: A Forty Year Perspective.”. Pp. 215-46 in Frontiers in the Economics of Aging, edited by David Wise. Chicago, IL: University of Chicago Press.

Fonseca, R. P-C. Michaud, T. Galama, and A. Kapteyn, 2009 “On the Rise of Health Spending and Longevity.” IZA DP No. 4622.

Jin, L. and N.A. Christakis. 2009. “Investigating the Mechanism of Marital Mortality Reduction: The Transition to Widowhood and Quality of Health Care.” Demography 46(3):605-25.

Juster, F. T. and J.P. Smith. 1997. “Improving the Quality of Economic Data: Lessons from the HRS and AHEAD,” Journal of the American Statistical Association 92(440):1268-78.

Juster F.T and R. Suzman. 1995. “An Overview of the Health and Retirement Study.” Journal of Human Resources 30:S7, S56. 
Kitagawa, E.M and P. Hauser. 1973. Differential Mortality in the United States: A Study in Socio-Economic Epidemiology. Cambridge, MA: Harvard University Press.

Lynch, J., S. Harper, G.A. Kaplan, and G.D. Smith. 2004. “Associations Between Income Inequality and Mortality Among U.S. States: The Importance of Time Period and Source of Income Data.” American Journal of Public Health 95:1424-30.

Manton, K. and J. Vaupel. 1995. "Survival After Age 80 in the United States, Sweden, France, England, and Japan.” New England Journal of Medicine 333(18):1232-5.

Melia J, S. Moss, and L. Johns. 2004. "Rates of Prostate-specific Antigen Testing in General Practice in England and Wales in Asymptomatic and Symptomatic Patients: A Crosssectional Study.” British Journal of Urology International 94:51-6.

Mirowdky, J. and C. Ross. 2003. Education, Social Status, and Health. New York: Aldine De Gruyter.

Preston, S.H. and J.Y. Ho. 2009a. "Low Life Expectancy in the United States-Is the Health Care System at Fault?” National Bureau of Economic Research Working Paper 15213.

Preston, S.H. and J.Y. Ho. 2009b. "US Mortality in an International Context: Age Variations.” Population Studies Paper Series, University of Pennsylvania, PSC- 09-04.

Rogers, R.G., R.A. Hummer, and C.B. Nam. 2000. Living and Dying in the USA: Behavioral, Health, and Social Differentials of Adult Mortality. San Diego: Academic Press.

Sirovich, B.E., L.M. Schwartz, and S. Woloshin. 2003 “Screening Men for Prostate and Colorectal Cancer in the United States: Does Practice Reflect the Evidence?” JAMA 289:1414-20.

Smith, J.P. 1999. "Healthy Bodies and Thick Wallets: The Dual Relation between Health and Economic Status.” Journal of Economic Perspectives 13(2):145-67. 
Smith, J.P. 2004. "Unraveling the SES-Health Connection.” Population and Development Review Supplement: Aging, Health and Public Policy: Demographic and Economic Perspectives, 30:108-132.

UK Government Actuary's Department Interim Life Tables (available at http://www.gad.gov.uk/Demography Data/Life Tables/index.html).

Waite, L. and M. Gallagher. 2000. The Case for Marriage: Why Married People Are Happier, Healthier, and Better Off Financially. New York: Doubleday. 
Table 1

Estimates of Disease Prevalence

\begin{tabular}{|c|c|c|c|c|c|c|c|}
\hline Ages 55-64 & Stroke & Lung & Cancer & HBP & Diabetes & Heart & $\begin{array}{l}\text { Heart } \\
\text { Attack }\end{array}$ \\
\hline England: ELSA 2002 & 2.28 & 5.62 & 5.48 & 33.40 & 5.88 & 8.21 & 4.05 \\
\hline US: $\quad$ HRS 2002 & 3.52 & 8.22 & 9.57 & 42.65 & 12.07 & 15.50 & NA \\
\hline England: HSE 2003 & 2.39 & $\mathrm{NA}$ & NA & 38.89 & 5.73 & 8.37 & 4.49 \\
\hline US: $\quad$ NHIS 2002 & 3.00 & NA & 8.19 & 39.58 & 11.34 & 19.31 & 5.43 \\
\hline $\begin{array}{l}\text { England: ELSA Balanced } \\
\text { sample all } 3 \text { waves }\end{array}$ & 1.84 & 4.55 & 5.06 & 32.97 & 5.57 & 7.61 & 3.69 \\
\hline $\begin{array}{l}\text { US: HRS Balanced } \\
\text { sample all } 3 \text { waves }\end{array}$ & 3.43 & 7.57 & 8.97 & 41.78 & 11.44 & 14.28 & NC \\
\hline
\end{tabular}

\begin{tabular}{|c|c|c|c|c|c|c|c|}
\hline Ages- 70-80 & Stroke & Lung & Cancer & HBP & Diabetes & Heart & $\begin{array}{l}\text { Heart } \\
\text { Attack }\end{array}$ \\
\hline England: ELSA 2002 & 7.17 & 8.28 & 7.80 & 47.67 & 10.38 & 20.99 & 10.01 \\
\hline US: $\quad$ HRS 2002 & 8.42 & 12.26 & 17.92 & 59.00 & 17.23 & 32.06 & NA \\
\hline England: HSE 2003 & 8.78 & NA & NA & 51.47 & 9.92 & 18.94 & 9.23 \\
\hline US: $\quad$ NHIS 2002 & 8.16 & NA & 16.34 & 54.25 & 15.95 & 34.18 & 12.67 \\
\hline $\begin{array}{l}\text { England: ELSA Balanced } \\
\text { sample all } 3 \text { waves }\end{array}$ & 5.86 & 7.28 & 7.03 & 48.00 & 9.38 & 18.94 & 8.76 \\
\hline $\begin{array}{l}\text { US: HRS Balanced } \\
\text { sample all } 3 \text { waves }\end{array}$ & 6.63 & 9.87 & 16.74 & 56.64 & 15.30 & 28.47 & NC \\
\hline
\end{tabular}


Table 2

Estimates of Disease Incidence_-England and US

\begin{tabular}{llllllll}
\hline \multicolumn{1}{c}{ Ages 55-64 } & Stroke & Lung & Cancer & HBP & Diabetes & Heart & $\begin{array}{c}\text { Heart } \\
\text { Attack }\end{array}$ \\
\hline $\begin{array}{l}\text { England: In both } \\
2002 \text { and 2006 }\end{array}$ & 1.70 & 2.00 & 2.99 & 10.17 & 3.33 & 2.61 & 1.85 \\
$\begin{array}{l}\text { ELSA } \\
\begin{array}{l}\text { US: In both 2002 } \\
\text { and 2006 HRS- }\end{array}\end{array}$ & 2.07 & 3.08 & 4.26 & 10.03 & 6.00 & 6.25 & 3.31 \\
$\begin{array}{l}\text { England: HSE 2006 } \\
\text { minus HSE 2003 }\end{array}$ & 1.19 & NA & NA & 5.97 & 2.75 & NA & 0.25 \\
$\begin{array}{l}\text { US: NHIS 2002] } \\
\text { minus NHIS 2006 }\end{array}$ & 2.19 & NC & 3.10 & 10.09 & 5.31 & 5.79 & 2.51 \\
\hline
\end{tabular}

Estimates of Disease Incidence_-England and US

\begin{tabular}{lccccccc}
\hline \multicolumn{1}{c}{ Ages 70-80 } & Stroke & Lung & Cancer & HBP & Diabetes & Heart & $\begin{array}{r}\text { Heart } \\
\text { Attack }\end{array}$ \\
\hline $\begin{array}{l}\text { In both waves 1 and } \\
\text { 3-ELSA }\end{array}$ & 4.68 & 2.78 & 4.80 & 9.83 & 4.44 & 4.80 & 3.38 \\
$\begin{array}{l}\text { US- 2002-2006- } \\
\text { HRS }\end{array}$ & 5.51 & 3.89 & 5.88 & 8.31 & 4.66 & 9.28 & 5.42 \\
$\begin{array}{l}\text { England: HSE 2006 } \\
\text { minus HSE 2003 }\end{array}$ & 3.15 & NC & NC & 4.40 & 5.55 & NC & 2.95 \\
$\begin{array}{l}\text { US: NHIS 2002 } \\
\text { minus NHIS 2006 }\end{array}$ & 1.91 & NC & 3.64 & 10.56 & 4.22 & 4.05 & 2.34 \\
\hline
\end{tabular}

NA-not available

Sources: England—2002 English Longitudinal Survey of Ageing (ELSA) and 2003 Health Survey for England (HSE): United States_-2002 Health and Retirement Survey (HRS) and 2002 National Health Interview Survey (NHIS). 
Table 3

A. Estimates of Financial Gradients, Ages 55-64

(1)

(2)

(3)

(4)

(2) + Health

(1)+ Age, Behaviors, (3) + Health

Quintile

None

Gender Work, Married

Status

A. USA

$\begin{array}{lll}1 & 0.053^{* *} & 0.055^{* *} \\ 2 & 0.030^{* *} & 0.032^{* *} \\ 3 & 0.017 & 0.017 \\ 4 & 0.015 & 0.014\end{array}$

(a) Income

$\begin{array}{ll}0.020 & 0.004 \\ 0.010 & 0.009 \\ 0.004 & 0.006 \\ 0.006 & 0.009\end{array}$

$\begin{array}{lll}1 & 0.055^{* *} & 0.055^{* *} \\ 2 & 0.009 & 0.009 \\ 3 & 0.022^{*} & 0.022^{*} \\ 4 & -0.005 & -0.004\end{array}$

(b) Wealth

$\begin{array}{rr}0.033^{* *} & 0.015 \\ -0.000 & -0.001 \\ 0.016 & 0.015 \\ -0.007 & -0.004\end{array}$

B. England

$\begin{array}{lllcc}1 & 0.039^{* *} & 0.038^{* *} & 0.016 & 0.014 \\ 2 & 0.047^{* *} & 0.045^{* *} & 0.027^{* *} & 0.023^{*} \\ 3 & 0.009 & 0.008 & -0.000 & -0.001 \\ 4 & 0.007 & 0.008 & 0.002 & 0.004\end{array}$

\begin{tabular}{lllll}
1 & $0.054^{* *}$ & $0.053^{* *}$ & $0.037^{* *}$ & $0.028^{*}$ \\
2 & $0.029^{* *}$ & $0.029^{* *}$ & $0.021^{*}$ & 0.015 \\
3 & $0.021^{*}$ & $0.020^{*}$ & 0.019 & $0.018^{*}$ \\
4 & 0.009 & 0.011 & 0.010 & 0.010 \\
\hline
\end{tabular}

B. Estimates of Financial Gradients, Ages 70-80

\section{A. USA}

$\begin{array}{lllcl} & & & \text { (a) Income } \\ 2 & 0.135^{* *} & 0.140^{* *} & 0.083^{* *} & 0.036 \\ 3 & 0.076^{* *} & 0.073^{* *} & 0.035 & 0.020 \\ 4 & 0.066^{* *} & 0.060^{* *} & 0.036 & 0.030 \\ & 0.022 & 0.021 & 0.011 & 0.007 \\ 1 & & & \text { (b) Wealth } \\ 2 & 0.134^{* *} & 0.137^{* *} & 0.089 * * & 0.044^{*} \\ 3 & 0.088^{* *} & 0.093^{* *} & 0.066^{* *} & 0.045^{*} \\ 4 & 0.052^{* *} & 0.055^{* *} & 0.031 & 0.026 \\ & 0.036^{*} & 0.037^{*} & 0.028 & 0.026\end{array}$


B. England

\begin{tabular}{lllll} 
& \multicolumn{3}{c}{ (a) Income } \\
1 & 0.017 & 0.032 & -0.033 & -0.036 \\
2 & -0.004 & -0.004 & $-0.041^{*}$ & $-0.040^{*}$ \\
3 & 0.031 & 0.031 & -0.001 & -0.009 \\
4 & 0.008 & 0.007 & -0.015 & -0.017 \\
& & & (b) Wealth & \\
1 & $0.089^{* *}$ & $0.102^{* *}$ & $0.067^{*}$ & 0.040 \\
2 & $0.084^{* *}$ & $0.088^{* *}$ & $0.068^{*}$ & $0.056^{*}$ \\
3 & 0.014 & 0.018 & 0.002 & 0.005 \\
4 & 0.004 & 0.013 & 0.008 & 0.001
\end{tabular}

Sources: Calculations by authors, USA —HRS 2002-2006; England_ELSA 2002-2006.

$* *=$ significant at $1 \%$ level

$*=$ significant at $5 \%$ level 
Table 4

Percent Distribution of Attributes by Income and Wealth Quintiles

Ages 55-64-United States and England

\begin{tabular}{|c|c|c|c|c|c|c|}
\hline & \multicolumn{3}{|c|}{ US } & \multicolumn{3}{|c|}{ England } \\
\hline & \multicolumn{3}{|c|}{ Income quintiles } & \multicolumn{3}{|c|}{ Income quintiles } \\
\hline & $1^{\mathrm{st}}$ & $3-1$ & $5-1$ & $1 \mathrm{st}$ & 3-1 & $5-1$ \\
\hline \multicolumn{7}{|l|}{ Behavior Variables } \\
\hline Obese & 0.291 & 0.021 & $-0.086 * *$ & 0.267 & -0.002 & $-0.070 * *$ \\
\hline Smoke Now & 0.297 & $-0.095 * *$ & $-0.175 * *$ & 0.328 & $-0.105 * *$ & $-0.191 * *$ \\
\hline Smoke Ever & 0.669 & $-0.053 * *$ & $-0.107 * *$ & 0.673 & -0.017 & -0.045 \\
\hline Heavy drinking & 0.056 & 0.019 & $0.077^{* *}$ & 0.225 & 0.032 & $0.229 * *$ \\
\hline Moderate drinking & 0.178 & $0.109 * *$ & $0.251^{* *}$ & 0.317 & 0.037 & 0.012 \\
\hline Weeks Worked & 14.1 & $22.4^{* *}$ & $25.1^{* *}$ & 12.8 & $16.7 * *$ & $25.0 * *$ \\
\hline Vigorous Exercise & 0.380 & $0.115^{* *}$ & $0.166^{* *}$ & 0.255 & $0.059 *$ & $0.153^{* *}$ \\
\hline Married & 0.501 & $0.359 * *$ & $0.439 * *$ & 0.517 & $0.291^{* *}$ & $0.378^{* *}$ \\
\hline \multicolumn{7}{|l|}{ Health Status Variables } \\
\hline Health Excellent/Very Good & 0.315 & $0.199 * *$ & $0.374 * *$ & 0.324 & $0.144^{* *}$ & $0.243^{* *}$ \\
\hline Hypertension & 0.461 & -0.015 & $-0.082 * *$ & 0.357 & 0.001 & $-0.066 * *$ \\
\hline Diabetes & 0.168 & $-0.044^{* *}$ & $-0.091^{* *}$ & 0.062 & 0.013 & -0.018 \\
\hline Cancer & 0.114 & -0.008 & -0.015 & 0.057 & -0.007 & -0.002 \\
\hline Lung & 0.144 & $-0.057 * *$ & $-0.105^{* *}$ & 0.089 & $-0.039 * *$ & $-0.052 * *$ \\
\hline Heart & 0.226 & $-0.049 * *$ & $-0.118 * *$ & 0.109 & -0.021 & $-0.060 * *$ \\
\hline Stroke & 0.068 & $-0.039 * *$ & $-0.052 * *$ & 0.038 & -0.017 & -0.030 \\
\hline \multirow[t]{3}{*}{ Arthritis } & 0.606 & $-0.069 * *$ & $-0.226 * *$ & 0.343 & -0.071 & $-0.125 * *$ \\
\hline & \multicolumn{3}{|c|}{ Wealth quintiles } & \multicolumn{3}{|c|}{ Wealth quintiles } \\
\hline & $1^{\text {st }}$ & 3-1 & $5-1$ & 1st & 3-1 & 5-1 \\
\hline \multicolumn{7}{|l|}{ Behavior Variables } \\
\hline Obese & 0.366 & $-0.088 * *$ & $-0.159 * *$ & 0.341 & $-0.093 * *$ & $-0.143^{* *}$ \\
\hline Smoke Now & 0.336 & $-0.154 * *$ & $-0.220 * *$ & 0.408 & $-0.218^{* *}$ & $-0.297 * *$ \\
\hline Smoke Ever & 0.740 & $-0.127 * *$ & $-0.213^{* *}$ & 0.746 & $-0.104^{* *}$ & $-0.177 * *$ \\
\hline Heavy drinking & 0.054 & $0.026 *$ & $0.080 * *$ & 0.179 & $0.077 * *$ & $0.288 * *$ \\
\hline Moderate drinking & 0.178 & $0.099 * *$ & $0.217 * *$ & 0.291 & $0.097 * *$ & 0.029 \\
\hline Weeks Worked & 23.7 & $5.1^{* *}$ & $3.3^{* *}$ & 20.6 & $10.1^{* *}$ & $9.6^{* *}$ \\
\hline Vigorous Exercise & 0.341 & $0.151^{* *}$ & $0.257 * *$ & 0.185 & $0.133^{* *}$ & $0.249 * *$ \\
\hline Married & 0.564 & $0.283^{* *}$ & $0.341 * *$ & 0.551 & $0.237 * *$ & $0.313^{* *}$ \\
\hline \multicolumn{7}{|l|}{ Health Status Variables } \\
\hline Health Excellent/Very Good & 0.278 & $0.263 * *$ & $0.369 * *$ & 0.284 & $0.167 * *$ & $0.356 * *$ \\
\hline Hypertension & 0.521 & $-0.100 * *$ & $-0.160 * *$ & 0.397 & $-0.070 * *$ & $-0.132 * *$ \\
\hline Diabetes & 0.183 & $-0.056 * *$ & $-0.114^{* *}$ & 0.077 & -0.023 & -0.040 \\
\hline Cancer & 0.109 & -0.016 & -0.003 & 0.052 & -0.006 & 0.008 \\
\hline Lung & 0.161 & $-0.096 * *$ & $-0.116^{* *}$ & 0.115 & $-0.069 * *$ & $-0.091 * *$ \\
\hline Heart & 0.244 & $-0.086^{* *}$ & $-0.111^{* *}$ & 0.131 & $-0.049 * *$ & $-0.086 * *$ \\
\hline Stroke & 0.081 & $-0.052 * *$ & $-0.064^{* *}$ & 0.049 & $-0.030 * *$ & $-0.039 * *$ \\
\hline Arthritis & 0.612 & $-0.105 * *$ & $-0.173 * *$ & 0.368 & $-0.082 * *$ & $-0.174 * *$ \\
\hline
\end{tabular}

Sources: Calculations by authors. USA-HRS 2002-2006; England-ELSA 2002-2006.

$* *=$ significant at $1 \%$ level $*=$ significant at $5 \%$ level 
Table 5

Percent Distribution of Attributes by Income and Wealth Quintiles

Ages 70-80—United States and England

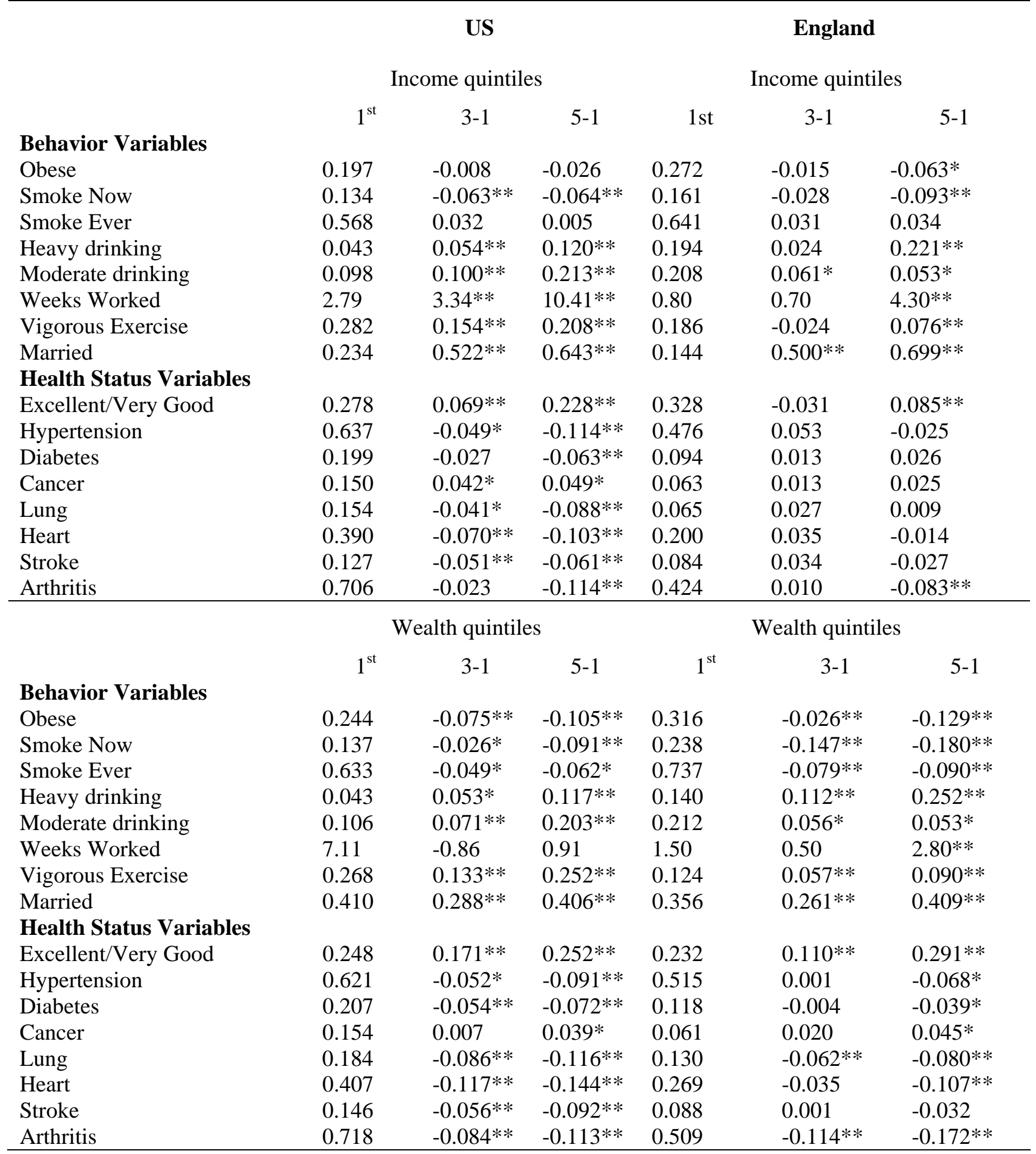

Sources: Calculations by authors. USA—HRS 2002-2006; England-ELSA 2002-2006.

$* *$ = significant at $1 \%$ level

$*=$ significant at $5 \%$ level 
Table 6

The Impact of Excluding Capital Income on Income Gradients USA, Ages 70-80, Coefficients excluding capital income in Parentheses

\begin{tabular}{cllll}
\hline & \multicolumn{5}{c}{ Controls } \\
\cline { 2 - 5 } Income & \multicolumn{5}{c}{$\begin{array}{c}+ \text { + Health } \\
\text { Qehaviors, } \\
\text { Quintile }\end{array}$} & \multicolumn{4}{c}{ None } & \multicolumn{4}{c}{ Age, Gender } & Work, Married & + + Health \\
\hline \multicolumn{4}{c}{ Income } \\
1 & $0.135^{* *}\left(.102^{* *}\right)$ & $0.140^{*}\left(.101^{* *}\right)$ & $0.083^{* *}\left(.042^{*}\right)$ & $0.036^{*}(.006)$ \\
2 & $0.076^{* *}\left(.065^{* *}\right)$ & $0.073^{*}\left(.056^{* *}\right)$ & $0.035^{*}(.019)$ & $-0.020(-.002)$ \\
3 & $0.066^{* *}\left(.065^{* *}\right)$ & $0.060^{*}\left(.055^{* *}\right)$ & $0.036^{*}\left(.031^{*}\right)$ & $0.030^{*}\left(.029^{*}\right)$ \\
4 & $0.022(.019)$ & $0.021(.011)$ & $0.011(-.001)$ & $0.007(-.006)$ \\
\hline
\end{tabular}

Sources: Calculations by authors. USA—HRS 2002-2006. 
Table 7

Estimated Effects of Predicting US Mortality by Quintiles of Changes in Wealth (1992-2002) ("t" statistics in parenthesis)

\begin{tabular}{|c|c|c|c|c|}
\hline \multirow{2}{*}{$\begin{array}{l}\text { Quintile of } \\
\text { change in } \\
\text { wealth } \\
\text { 1992-2002 }\end{array}$} & \multicolumn{3}{|c|}{ Estimated coefficients on change in wealth } & \multirow{2}{*}{$\begin{array}{l}\text { Median within } \\
\text { Quintile Change }\end{array}$} \\
\hline & $\begin{array}{l}\text { (1) } \\
\text { Controls: age, } \\
\text { gender and } \\
\text { wealth in } 1992\end{array}$ & $\begin{array}{l}\text { (2) } \\
\text { Controls: as (1) } \\
\text { plus behaviors) }\end{array}$ & $\begin{array}{c}\text { (3) } \\
\text { Controls: as (2) } \\
\text { plus health) }\end{array}$ & \\
\hline 1 & $0.028 \quad(2.67)$ & $0.020(1.92)$ & $0.017 \quad(1.59)$ & $-96,000$ \\
\hline 2 & 0.014 & $0.004(0.32)$ & $0.003(0.26)$ & 500 \\
\hline 3 & 0.001 & $-0.018(0.16)$ & $-0.001 \quad(0.27)$ & 44,300 \\
\hline 4 & $-0.003(0.24)$ & $-0.002(0.18)$ & $0.002(0.14)$ & 133,000 \\
\hline 5 & & & & 455,000 \\
\hline
\end{tabular}

Sources: Calculations by authors. USA—HRS 1992-2002. 


\section{Figure 1}

Age specific survival probabilities: HRS vs. Life

\section{Tables}

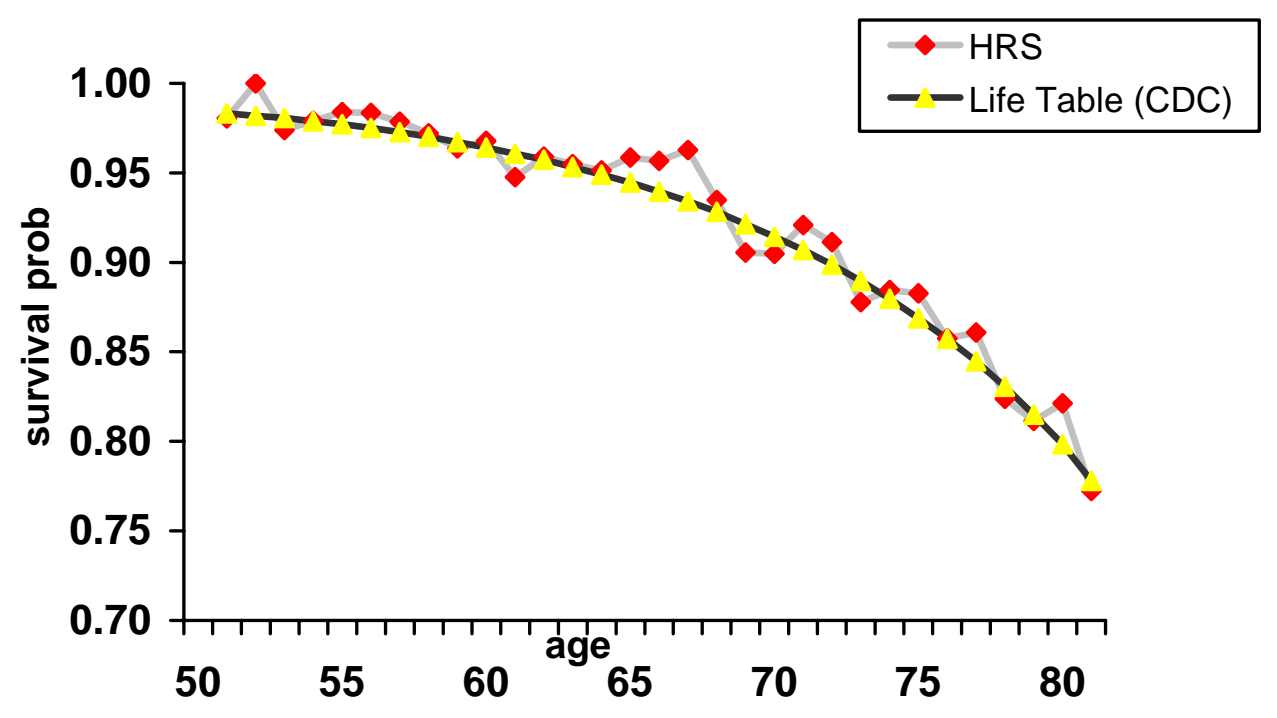

Sources: Author's calculations using HRS 2002-2006 and Center for Disease Control 2002 life table (Arias 2004). 
Figure 2

Age specific survival probabilities: ELSA vs. Life Tables

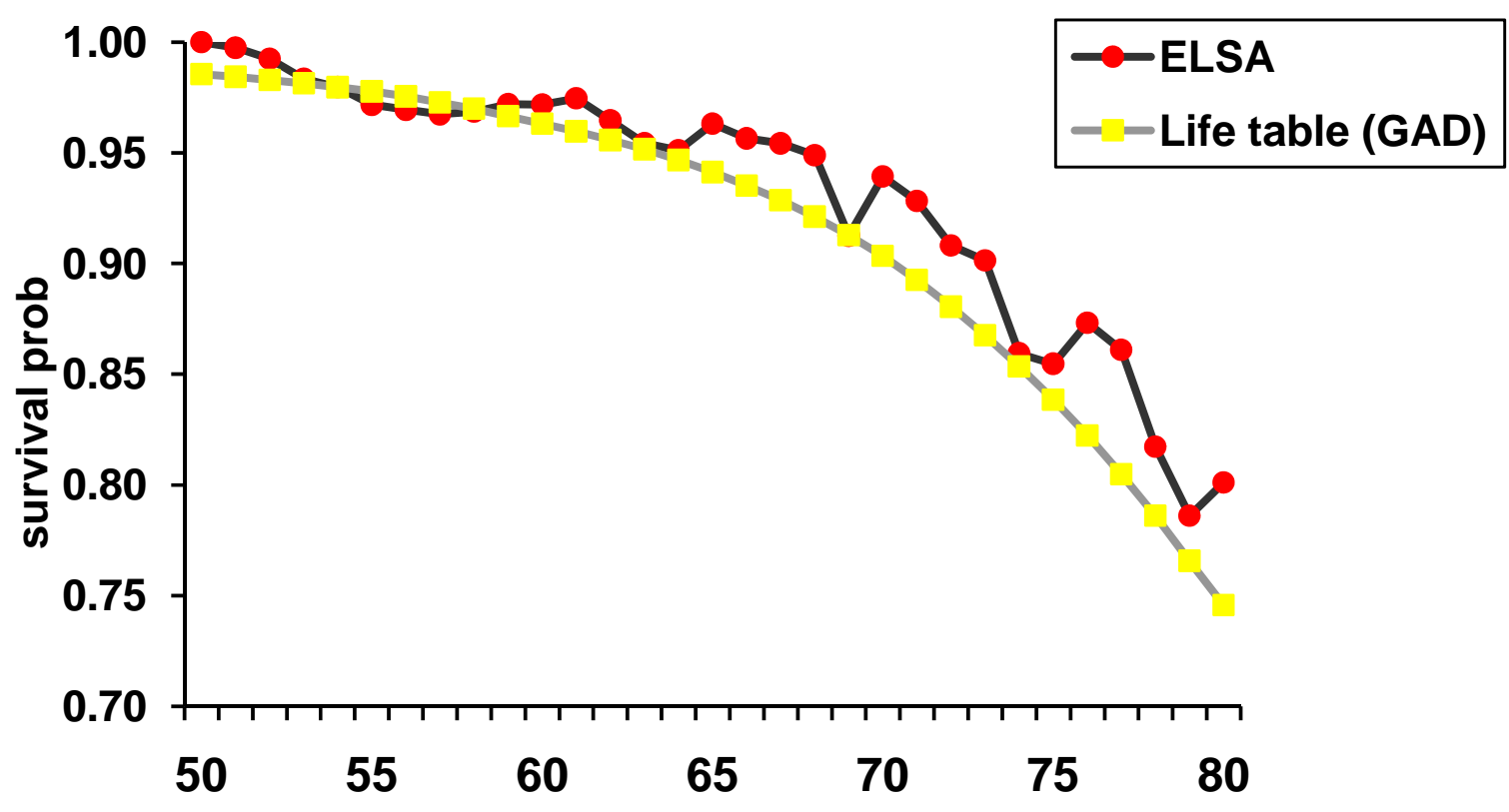

aqe

Sources: Author's calculations using ELSA and the Government Actuary Department Interim 2002 Life Tables. 
Figure 3.A

Age specific survival probabilities: GAD and CDC Life Tables

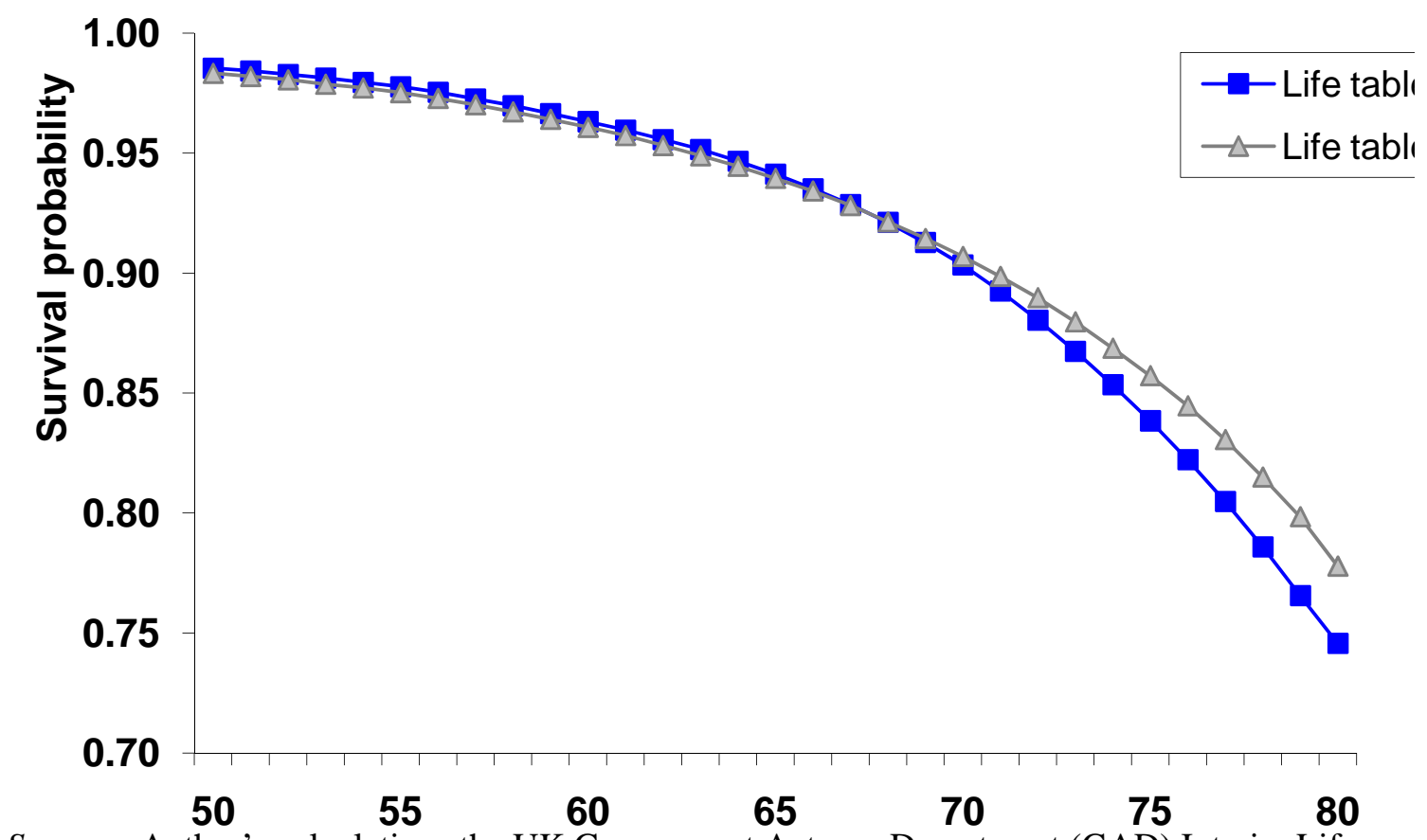

Sources: Author's calculations the UK Government Actuary Department (GAD) Interim Life

Tables and CDC for the United States (Arias 2004). Life Tables are for 2002.

\section{Figure 3.B}

\section{Age specific survival probabilities: HRS vs. ELSA}

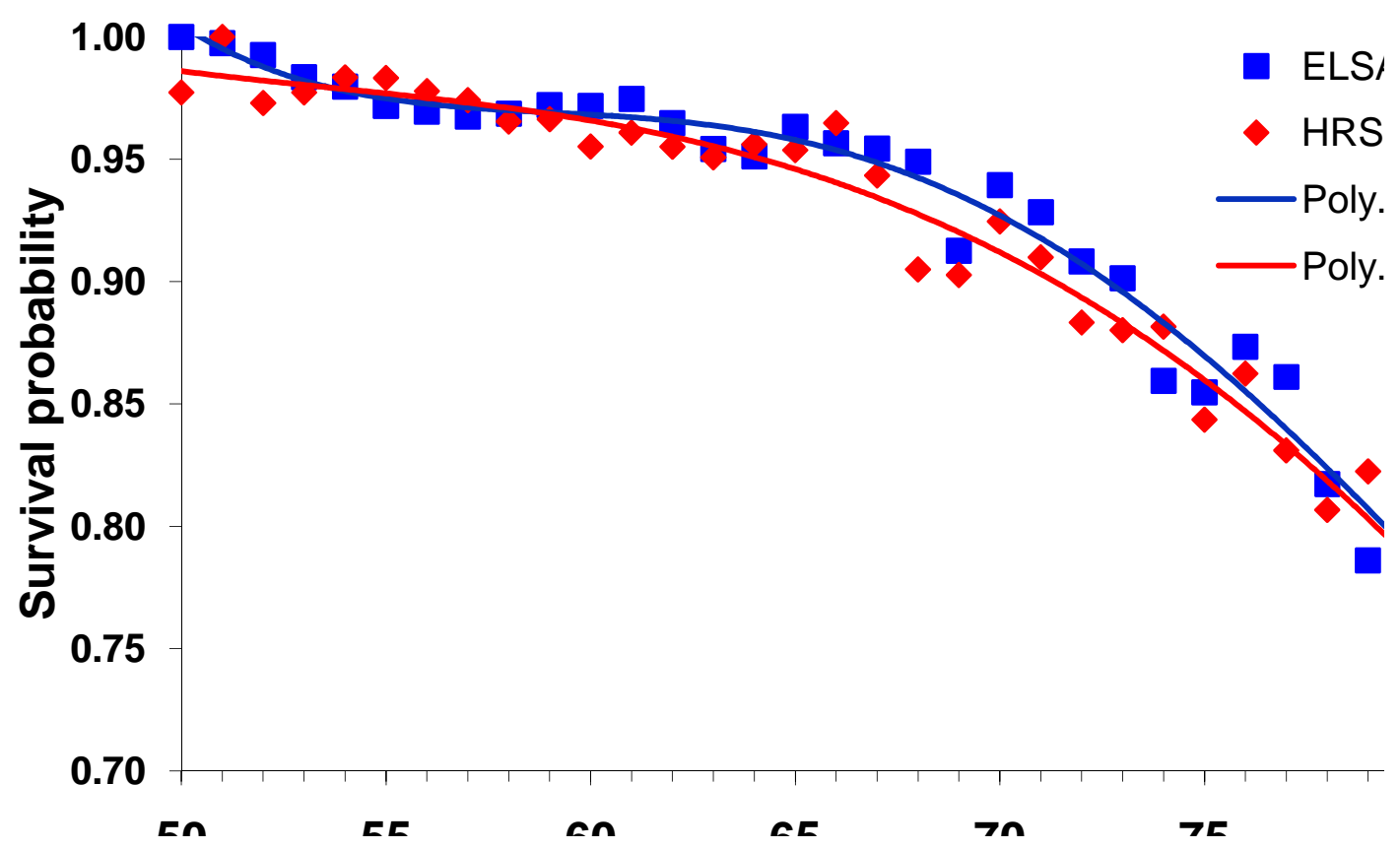

Sources: Author's calculations using HRS and ELSA. Trend lines are fourth order polynomials fitted to ELSA and HRS data. 
Figure 4

Sources of Income in England (70 to 80 year olds)

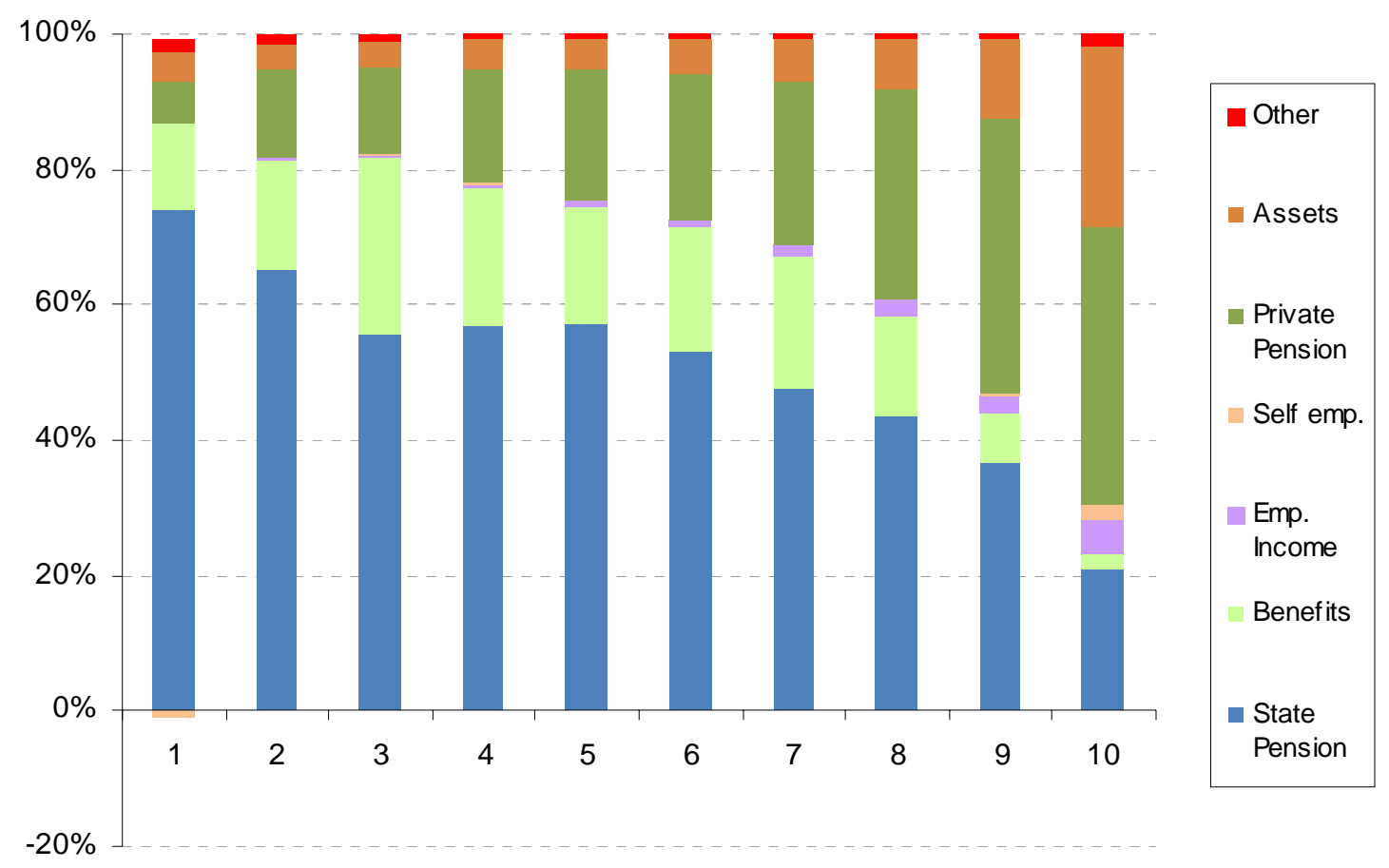

Sources: Authors calculations using the 2002-2003 Family Resource Survey. 